\title{
Factors influencing consent rates of deceased organ donation in Western Cape Province, South Africa
}

\author{
H Bookholane, ${ }^{1}$ MB ChB; A Michaelides, ${ }^{2}$ RN, RM, Dip ICU, Dip TPM (U Barcelona); L Prins, ${ }^{2}$ RN, RM, Crit Care Honours, Nursing Pharmacol; \\ L Steenkamp, ${ }^{3} \mathrm{RN}$, Dip Crit Care TE; B Gili, ${ }^{3,4}$ BCur (Basic), Dip ICU, Dip Nursing Management; \\ F McCurdie, ${ }^{3}$ BSc (Nursing), RN, RM, Dip ICU; L Human, ${ }^{2}$ RN, Dip ICU; D Thomson, ${ }^{1}$ MB ChB, FCS (SA), MMed (Surgery), Cert Crit Care (SA) \\ ${ }^{1}$ Department of Surgery, Faculty of Health Sciences, University of Cape Town and Groote Schuur Hospital, Cape Town, South Africa \\ ${ }^{2}$ Netcare Transplant Division, Cape Town, South Africa \\ ${ }^{3}$ Groote Schuur Hospital, Cape Town, South Africa \\ ${ }^{4}$ Red Cross War Memorial Children's Hospital, Cape Town, South Africa
}

Correspondingauthor: D Thomson (david.thomson@uct.ac.za)

Background. South Africa (SA) has very low and unchanging organ donation rates. A key point in the pathway of organ donation is obtaining informed consent from the family, which is necessary before organ donation can proceed. There is no published SA research on the consent rate and factors that influence this.

Objectives. To describe the number of requests for consent and factors influencing this process in the SA context.

Methods. A prospective descriptive study was performed of all requests to families for organ donation in Western Cape Province, SA, by Groote Schuur Hospital (state sector), Red Cross War Memorial Children's Hospital (state sector) and Netcare (private sector) transplant co-ordinators from 1 May 2017 to 1 May 2018 to describe factors influencing consent rates.

Results. The 6 co-ordinators ( 3 state sector and 3 private sector) recorded data of 83 consecutive families approached in 16 hospitals over the 1 -year period. Consent to organ donation was granted for 23 family requests ( $n=18$ (state sector); $n=5$ (private sector)). The number of families approached was greater in the state sector $(n=74)$ than in the private sector $(n=9)$. The overall consent rate was $27.7 \%(24.3 \%$ (state sector); $55.5 \%$ (private sector)). The majority of referrals came from trauma and emergency units $(n=55 ; 66.3 \%)$ and very few from intensive care units $(n=25 ; 30.1 \%)$. Immediate fluid resuscitation was required in $56(67.5 \%)$ potential donors. The majority of families $(n=74 ; 89.2 \%)$ were receptive to the organ donation request, independent of their ultimate decision regarding donation. The main reason given for refusing to consent was that it was against their religion $(n=21)$ or culture $(n=18)$.

Conclusions. This study showed that the number of families approached for consent to organ donation were low in the Western Cape (lower in the private sector), with a low consent rate (lower in the state sector). Donor management by clinical teams needs to be ongoing and active during the consent process. Consent discussions (and public awareness initiatives) need to be sensitive to and deal with religious and cultural reservations about organ donation.

S Afr Med J 2020;110(3):204-209. https://doi.org/10.7196/SAMJ.2020.v110i3.14227

South Africa (SA) has extremely low organ donation rates compared with the rest of the world. Donation rates have not changed significantly over the last 10 years (Table 1$){ }^{[1]}$

There are many potential reasons, which have not been studied well. Reasons that have been suggested are low numbers of donor referrals and low consent rates. In SA, there is currently no national strategy for the advancement of organ donation. High-performing systems, such as those in Spain, use ongoing quality-assurance mechanisms to ensure that all potential donors are identified, referred and managed appropriately, with specially trained professionals making an appropriately timed and sensitive approach to the family for consent. ${ }^{[2]}$ In the SA system, transplant co-ordinators are specialist nurses trained to request consent for organ donation, manage donors and arrange the logistics of organ recovery. In 2016, SA had only 22 such professionals. They are employed by individual hospitals or hospital groups, where they often also fulfil other functions. ${ }^{[3]}$

The Organ Donor Foundation (ODF) of SA is a public awareness organisation that maintains an organ donor database of intent to donate and does not function as an organ procurement or co-ordination body. ${ }^{[4]}$ The database is of limited use, as it is not

Table 1. Global Observatory on Donation and Transplantation: Deceased donor rates ${ }^{[1]}$

\begin{tabular}{llllll}
\hline Country & Population, million & $\begin{array}{l}\text { Deceased donors in } \\
\mathbf{2 0 1 7}, \boldsymbol{n}\end{array}$ & $\begin{array}{l}\text { Deceased donation } \\
\text { rate in 2017 }\end{array}$ & $\begin{array}{l}\text { Deceased donation } \\
\text { rate in 2007 }\end{array}$ & $\begin{array}{l}\text { Change in donor rate } \\
\text { over 10 years }\end{array}$ \\
\hline Australia & 24.5 & 510 & 20.82 & 9.61 & 11.21 \\
Brazil & 209.3 & 3420 & 16.34 & 5.48 & 10.86 \\
South Africa & 56.7 & 91 & 1.60 & 1.30 & 0.30 \\
Spain & 47.0 & 2183 & 47.05 & 35.55 & 12.50 \\
UK & 66.2 & 1492 & 22.54 & 13.22 & 9.32 \\
USA & 324.5 & 10286 & 31.70 & 26.60 & 5.10
\end{tabular}


available to transplant co-ordinators, and being registered on the organ donor database does not constitute legal consent in SA the family is always approached for consent. SA research has been published on knowledge of and attitudes to organ donation among medical students, ${ }^{[5]}$ urban-dwelling adults ${ }^{[6]}$ and the Zulu community ${ }^{[7]}$ distant from the grieving process. Favourable opinions regarding organ donation have been shown not to match the actual donation rate. ${ }^{[8]}$ There are no quantitative SA studies that have analysed factors influencing the consent process, despite this being an area consistently highlighted in national strategy documents to improve deceased donation and access to transplantation. ${ }^{[2,9]}$

We aim to describe factors influencing the consent rates in families approached for deceased donation in Western Cape Province, SA.

\section{Methods}

All medically suitable potential donor referrals resulting in a family approach for consent from 1 May 2017 to 1 May 2018 were recorded by transplant co-ordinators working for state (Groote Schuur Hospital and Red Cross War Memorial Children's Hospital) and private (Netcare) hospitals in the Western Cape. All private hospitals in the Western Cape and state hospitals in the Metro West area of Cape Town were covered. Data were prospectively entered on a structured data collection sheet after the transplant co-ordinator made a standard approach for consent. It was not required that the family report data points.

The following data points were recorded: cause of death; location of referral (hospital and unit); time of admission and brain death certification; condition of potential donor at time of referral; whether the unit was busy or overcrowded; consent decision; whether consent was granted; the organs consented for; reasons for consent refusal; time spent with family; individual(s) introducing the topic of organ donation; family knowledge of prognosis; family decision-makers; number of family members present; and family knowledge of organ donation. Reasons for consent refusal were selected from a list of checkbox options, allowing for multiple reasons to be chosen.

The deceased donor rate was calculated per million population (pmp) using population statistics from the Western Cape Department of Health data based on Census 2011, with an uninsured population rate of $74.8 \%$. The drainage area of the Metro West Cape Town Municipality (Klipfontein, Mitchell's Plain, Western and Southern) and drainage areas of the West Coast, Eden and Karoo districts were used to compute the state sector population serviced by the state co-ordinators, while all insured patients in the Western Cape were included as the private sector population.

Data were analysed in a password-secured Microsoft Excel (Microsoft, USA) database. Categorical data were summarised as frequencies and proportions. No comparative statistical analysis was performed owing to low sample size and inadequate power.

\section{Ethical approval}

The study was approved by the Human Research Ethics Committee of the University of Cape Town (ref. no. HREC 837/2016). The need for informed consent was waived, as the study was felt to be of minimal risk, in the public interest and not practicable without the waiver.

\section{Results}

The 6 transplant co-ordinators ( 3 state sector and 3 private sector) completed data on 83 families approached in 16 hospitals over the 1 -year period. The outcomes of the consent requests are given in Table 2 .

Over the initial 1-year period of this study, the most active centres were Groote Schuur Hospital (55 approaches) and Red Cross War
Memorial Children's Hospital (13 approaches), with only 1 private hospital, Vergelegen Mediclinic, having $>1$ approach (2 approaches). In the public sector, the consent rate was $24.3 \%(n=18 / 74)$, while in the private sector it was $55.5 \%(n=5 / 9)$. The overall donation rate was $5.59 \mathrm{pmp}$. In the private sector, the rate was $3.01 \mathrm{pmp}$ and in the Groote Schuur Hospital drainage area it was $7.34 \mathrm{pmp}$.

In $70 \%$ of cases, brain death was diagnosed within 24 hours of admission. In the state sector, $74.4 \%$ of referrals were from outside of the intensive care unit (ICU), while all referrals in the private sector came after admission to the ICU (Table 3). In both healthcare systems, in all units where the family was approached there were family counselling rooms, although these were not always available ( $n=4$ (state sector); $n=2$ (private sector)) The units were consistently busy and crowded (41.9\% (state sector); $66.7 \%$ (private sector)).

In $89.2 \%(n=74)$ of cases, the family was receptive to organ donation discussion, independent of whether their decision was to support donation. The family discussion for consent included multiple individuals in $72.3 \%(n=60)$ of cases. A single decisionmaker was identified in 29 cases. Where an individual decisionmaker was identified, there were more males (59.3\%); however, individual female decision-makers were more likely to consent to donation $(n=8 / 13 ; 53.8 \%)$ than men $(n=7 / 19 ; 36.8 \%)$ (Table 4$)$.

Additional family members were contacted telephonically in 7 cases, with 1 successful consent. An interpreter was used in 2 cases, with the language of discussion being English in most cases $(n=69)$ or Afrikaans $(n=9)$. The language of discussion was not the home language of the transplant co-ordinator or the family members approached for consent in $26.5 \%$ of cases ( $n=20$ (isiXhosa); $n=2$ (Amharic)).

The average age of the main decision-maker was 49 (range 28 72) years. The next-of-kin was most frequently a husband, wife, partner or parents. In 7 cases a more distant relative was approached (aunt, uncle, cousin or grandparents). The responsible decisionmaker could not be tracked down in time in 1 case and consent was rescinded by 1 family after consultation with a friend.

Various reasons were given for refusal, with no explanation in 6 cases and $>1$ reason in 6 cases (Table 5). In 2 cases initial consent was obtained, which was subsequently withdrawn.

\section{Discussion}

In our study, organ donor rates were low. The low donation rate influences the number of patients dying on the waiting list and limits access to dialysis slots in the resource-constrained public sector. Factors influencing the donation rate differed between the public and private sectors. In the private sector, despite a higher consent rate (55\%), the low number of donors who consented (3.01 pmp) was driven by the low number of families approached for consent.

Similar problems have been shown in the UK, where a study of all ICU deaths showed that even when patients were on mechanical ventilation and brain death was likely to be present, formal brain testing was not done in $31.4 \%$ of cases. Furthermore, in $15 \%$ of cases where it had been confirmed, there was no documented consideration of or approach made for organ donation. ${ }^{[10]}$ In the SA context, distrust and unwillingness of clinicians to refer donors have been highlighted as a problem. ${ }^{[1]}$

In the state sector, the number of families approached for consent was higher, with the majority of referrals $(74.4 \%)$ coming from emergency or trauma units. The consent rate was lower in the state than the private sector, with only $24.3 \%$ of families consenting to organ donation. A lack of access to ICU beds and the need to approach families in a busy emergency unit may have influenced the consent rate. 
In our study, $48 \%$ of donor families also consented to tissue and eye donation. This is difficult to interpret, as not all organ donors are candidates for tissue and eye donation. For example, there is no age cut-off to donate kidneys if their function is assessed as adequate, while eye banks do not accept donors $>70$ years of age. It must be noted that families are required to give consent for each organ and for tissue donated. However, the decision to make an additional request for eye and tissue donation is left to the discretion of the transplant co-ordinator.

Various countries have enacted legislation that requires doctors to refer all potential donors. There is no such requirement in SA. ${ }^{[12]}$ In the UK, there are minimum notification criteria, while in the USA, there are clinical triggers for referral. ${ }^{[13]}$

In the USA, government funding for hospitals is dependent on their being compliant in referring all deceased persons for organ and tissue donation to a designated donor-procurement organisation. ${ }^{[15]}$ In SA, hospitals without transplant programmes do

\begin{tabular}{ll} 
Table 2. Referral and consent overview & \\
\hline Referral and consent & $\boldsymbol{n}(\%)$ \\
\hline Families approached & 83 \\
Consent granted & $23(27.7)$ \\
Consent refused & $60(72.3)$ \\
Organs donated & 97 \\
Solid organs consented per donor & \\
Tissue donors & ${ }^{\dagger}$ \\
${ }^{*}$ Kidneys counted as 2 organs. & 4.2 \\
${ }^{\dagger}$ Consent rate for tissue donation was $100 \%$ in the private sector. &
\end{tabular}

not consider organ donation a priority and do not employ personnel or fund infrastructure to support such donation. Netcare was the sole private employer of transplant co-ordinators in this study and their co-ordinators covered referrals from all private hospitals.

Doctors' reasons not to refer are often presumed medical unsuitability of the donor or a perception that asking would distress the family. ${ }^{[10]}$ In our study, $89.2 \%$ of families were receptive to the family discussion, independent of their decision to donate, which is in keeping with the international literature, where the approach for consent to donation has been shown not to distress the family. We did not record data on medically unsuitable referrals and the person responsible for the decision. In the UK, minimum notification criteria require that all potential donors are assessed for suitability, irrespective of whether there is an apparent medical contraindication (Table 6). ${ }^{[9]}$ This is because the assessment of donor suitability is best made by transplant teams. Transplants from extended-criteria donors have shown good results and offer a significant survival benefit over no transplant. In our study, clinical teams assessed donor suitability, which may have accounted for the low referral rates.

National legislative changes, such as presumed consent, are often touted as a way to improve organ donation rates, but families are still routinely approached for consent, with an option to refuse. The Spanish system, currently the highest-performing in the world, noted an increase in deceased donation only after the formation of a national co-ordinating body and other quality-assurance mechanisms 10 years after presumed consent legislation was enacted. ${ }^{[16,17]}$ The family refusal rate was $16.4 \%$, even with presumed consent. ${ }^{[2]}$ In a large study assessing the potential donor pool in the USA, it was concluded that resources were best invested 'to improve the process

\section{Table 3. Details of referrals (public and private sector)}

\begin{tabular}{|c|c|c|c|}
\hline & Public, $n(\%)$ & Private, $n(\%)$ & Total, $n(\%)$ \\
\hline Referrals & $74(89.2)$ & $9(10.8)$ & $83(100)$ \\
\hline \multicolumn{4}{|l|}{ Cause of death } \\
\hline Medical & $24(32.4)$ & $6(66.7)$ & $30(36.1)$ \\
\hline Surgical & $47(63.5)$ & $3(33.3)$ & $50(60.2)$ \\
\hline Not recorded & $3(4.1)$ & 0 & $3(3.6)$ \\
\hline \multicolumn{4}{|l|}{ Location of referral } \\
\hline Intensive care unit & $16(21.6)$ & $9(100)$ & $25(30.1)$ \\
\hline Emergency unit & $17(23.0)$ & 0 & $17(20.5)$ \\
\hline Trauma unit & $38(51.4)$ & 0 & $38(45.8)$ \\
\hline Not recorded & $3(4.1)$ & 0 & $3(3.6)$ \\
\hline \multicolumn{4}{|l|}{ Was the unit busy/overcrowded? } \\
\hline Yes & $31(41.9)$ & $6(66.7)$ & $37(44.6)$ \\
\hline No & $41(55.4)$ & $3(33.3)$ & $44(53.0)$ \\
\hline Not recorded & $2(2.7)$ & 0 & $2(2.4)$ \\
\hline \multicolumn{4}{|l|}{ Condition of donor at time of referral } \\
\hline Stable & $21(28.4)$ & $5(55.6)$ & $26(31.3)$ \\
\hline Requiring resuscitation with $\geq 1$ L fluid & $52(70.3)$ & $4(44.4)$ & $56(67.5)$ \\
\hline Not recorded & $4(5.4)$ & 0 & $4(4.8)$ \\
\hline \multicolumn{4}{|c|}{ Who was first to raise the topic of organ donation? } \\
\hline Transplant co-ordinator & $68(91.9)$ & 0 & $68(81.9)$ \\
\hline Treating doctor & $4(5.4)$ & $5(55.6)$ & $9(10.8)$ \\
\hline Treating nurse & 0 & $2(22.2)$ & $2(2.4)$ \\
\hline Family & $2(2.7)$ & $2(22.2)$ & $4(4.8)$ \\
\hline \multicolumn{4}{|l|}{ Was the family aware of the poor prognosis? } \\
\hline Yes & $41(55.4)$ & $8(88.9)$ & $49(59.0)$ \\
\hline No & $32(43.2)$ & $1(11.1)$ & $33(39.8)$ \\
\hline Not recorded & $1(1.4)$ & 0 & $1(1.2)$ \\
\hline
\end{tabular}


Table 4. Family knowledge and awareness of organ donation and decision-making dynamics

\begin{tabular}{|c|c|c|c|}
\hline & Consent granted, $n(\%)$ & Consent refused, $n(\%)$ & Total, $n(\%)$ \\
\hline \multicolumn{4}{|c|}{ Did the family have prior knowledge of organ donation? } \\
\hline Yes & $20(87.0)$ & $26(43.3)$ & $46(55.4)$ \\
\hline No & $3(13.0)$ & $30(37.5)$ & $33(39.8)$ \\
\hline Unable to assess & 0 & $4(6.7)$ & $4(4.8)$ \\
\hline \multicolumn{4}{|c|}{ Had the family discussed organ donation before? } \\
\hline Yes $^{*}$ & $8(34.8)$ & $4(6.7)$ & $12(14.5)$ \\
\hline No & $13(56.5)$ & $55(91.7)$ & $68(81.9)$ \\
\hline Unable to assess & $2(8.7)$ & $1(1.7)$ & $3(3.6)$ \\
\hline \multicolumn{4}{|c|}{ Would the potential donor have supported organ donation? } \\
\hline Yes & $12(52.2)$ & 0 & $12(14.5)$ \\
\hline No & $3(13.0)$ & $29(48.3)$ & $32(38.6)$ \\
\hline Unknown & $8(34.8)$ & $30(50.0)$ & $38(45.8)$ \\
\hline Not completed & 0 & $1(1.7)$ & $1(1.2)$ \\
\hline \multicolumn{4}{|c|}{ How many family members were present during the discussion? } \\
\hline$<2$ & $11(47.8)$ & $12(20.0)$ & $23(27.7)$ \\
\hline $2-5$ & $5(21.7)$ & $20(33.3)$ & $25(30.1)$ \\
\hline $6-10$ & $2(8.7)$ & $18(30.0)$ & $20(24.1)$ \\
\hline$>10$ & $5(21.7)$ & $10(16.7)$ & $15(18.1)$ \\
\hline Not completed & $1(4.3)$ & 0 & $1(1.2)$ \\
\hline \multicolumn{4}{|c|}{ Was the family receptive to the organ donation discussion? } \\
\hline Yes & $23(100)$ & $51(85.0)$ & $74(89.2)$ \\
\hline No & 0 & $9(15.0)$ & $9(10.8)$ \\
\hline \multicolumn{4}{|c|}{ Was the family aware of the poor prognosis? } \\
\hline Yes & $19(82.6)$ & $31(51.7)$ & $50(60.2)$ \\
\hline No & $4(17.4)$ & $29(48.3)$ & $33(39.8)$ \\
\hline \multicolumn{4}{|c|}{$\begin{array}{l}\text { Was the decision-making dynamic centred around one person or } \\
\text { a group? }\end{array}$} \\
\hline One individual & $15(68.2)$ & $17(27.9)$ & $29(34.9)$ \\
\hline Group & $7(31.8)$ & $44(72.1)$ & $54(65.1)$ \\
\hline \multicolumn{4}{|c|}{ What was the gender of the individual decision-maker? } \\
\hline Male & $7(46.7)$ & $12(70.6)$ & $19(59.4)$ \\
\hline Female & $8(53.3)$ & $5(29.4)$ & $13(40.6)$ \\
\hline \multicolumn{4}{|l|}{ Family religion $^{\dagger}$} \\
\hline Christian & $17(73.9)$ & $36(58.1)$ & $53(62.4)$ \\
\hline Muslim & $1(4.3)$ & $14(22.6)$ & $15(17.6)$ \\
\hline Judaism & $1(4.3)$ & 0 & $1(1.2)$ \\
\hline Secular & $1(4.3)$ & 0 & $1(1.2)$ \\
\hline Unable to assess & $3(13.0)$ & $12(19.4)$ & $15(17.6)$ \\
\hline \multicolumn{4}{|c|}{ Was a religious leader involved? } \\
\hline Yes & $1(4.3)$ & $6(10.0)$ & $7(8.4)$ \\
\hline No & $22(95.7)$ & $54(90.0)$ & 76 (91.6) \\
\hline
\end{tabular}

of obtaining consent in larger hospitals ( $>150$ beds) to maximize the rate of organ recovery. ${ }^{\text {[18] }}$

Other countries have formulated formal assessments of their system and postulated guidelines for improvement. It is these system changes that are most effective in improving organ donation. Restructuring and a focus on identifying all potential donors were key recommendations highlighted by the UK in their Organ Donation Taskforce report to improve their practice. ${ }^{[19]}$ By incorporating quality-assurance mechanisms to ensure that no opportunity for organ donation consideration is lost and that donors and their families are always appropriately supported at the end of life, one can improve referral and management of potential donors.
Our study showed that on referral to the transplant co-ordinator, the donor was often in need of immediate fluid resuscitation. Adequate support of the potential donor during end-of-life discussions is an essential component of a successful referral. Guidelines for the management of potential donors stress active fluid management with normal haemodynamic targets to preserve organ function during the consent process and, when consent is obtained, during the logistics of arranging the donor and recipient operations. ${ }^{[20,21]}$ Donor management is highly specialised, as brain-dead donors progress to circulatory collapse without active management, and conversion rates (the number of organs successfully transplanted per potential donor) are used as an outcome measure of donation. ${ }^{[15]}$ 
In the private sector, for all families approached, the topic of organ donation had been raised by non-transplant team staff. There is good evidence that consent rates are higher if the organ donation discussion is decoupled (completely separate) from initial discussions about the prognosis and if the request is made by specifically trained persons. ${ }^{[22]}$ In the state sector, where the topic of organ donation was most often initiated by the transplant co-ordinator, the consent rates were not higher. Pre-existing knowledge about organ donation was also lower in this group, with families less likely to have discussed organ donation.

The reasons given for refusal were varied, with 'against my religion' and 'against my culture' being the most commonly cited. These reasons highlight that engagement with community and religious leaders on organ donation is required to help change perceptions, as no religion or culture is against helping fellow human beings. The need for this engagement was further highlighted by 7 cases where a religious leader was consulted, resulting in only 1 successful consent. In Israel, engagement with religious leaders has helped to facilitate an attitudinal change towards organ donation. ${ }^{[23]}$ Furthermore, there are incentives to support deceased donation as credit towards being on the waiting list - should you ever need an organ. ${ }^{[24]}$ In the UK, a study of the most powerful slogan to induce people to sign up on the organ donor registry was: 'If you needed an organ, would you accept one?'[25]

Due to the low numbers in this study, we were unable to draw significant conclusions from the data relating to decision-making and family dynamics around consent. However, the complex nature of these discussions and the large number of people involved were apparent. Informed consent to donation requires only the legal nextof-kin to give permission, but end-of-life decision-making is often a family affair with complex group dynamics. ${ }^{[26]}$ Consent for donation, however, did seem more likely when a single decision-maker was approached. By law, only the signature of the legal next-of-kin is required, but the family dynamic often requires more than one

\section{Table 5. Reasons for refusal}

\begin{tabular}{ll} 
Table 5. Reasons for refusal & $\boldsymbol{n}$ \\
\hline Reason & 21 \\
\hline Against my religion & 18 \\
Against my culture & 5 \\
Unsure what the deceased would have wanted & 4 \\
Lack of acceptance of brain death & 4 \\
Desecration of the body & 3 \\
Deceased expressed wish not to be a donor & 2 \\
Other family decision-makers not present & 5 \\
Other reasons* & 6 \\
No explanation given & 68 \\
Total & \\
* Too much to deal with'; 'been through too much'; 'cannot imagine that'; 'emotional state \\
of family members'; family disagreement.
\end{tabular}

person to assent to organ donation. A culturally sensitive approach for consent takes into account family support structures/situations and may require consultation with family elders or specific persons. ${ }^{[27]}$ Consequently, the ODF has built into their campaign message that one must be sure to inform one's family about one's wish to be a donor.

Our study also showed that education efforts need to focus on what happens to the body (it is a controlled operation in theatre with a normal open-casket funeral possible after donation) and explain the unequivocal and final nature of brain death (no-one has ever recovered after being correctly clinically certified as brain dead), as desecration of the body and a lack of acceptance of brain death were also reasons given for consent refusal. Engagement between donation advocates and society, and religious and cultural leaders, is required.

In cases where a decision is made to withdraw mechanical ventilation in futile (non-beneficial) settings, it is possible in specific circumstances to be an organ donor. Currently, Groote Schuur Hospital and Red Cross War Memorial Children's Hospital are the only hospitals in SA where donation after circulatory death is done. ${ }^{[28]}$ In cases where the family do not accept the diagnosis of brain death, it allows for donation after circulatory death, as the donor would arrest upon withdrawal of ventilation within the time period that organ recovery is permitted. In the UK, $39 \%$ of donations were made after circulatory death. ${ }^{[29]}$ These are patients in whom ongoing mechanical ventilation and intensive organ support are futile and a decision is made with the family to palliate and extubate. In our study, we had only 1 consent request for donation after circulatory death. It was noted that among the low number of donor referrals in the private sector, 9 were made for patients who could have been considered for donation after circulatory death, but this is not supported in the private sector for logistical reasons and lack of institutional protocols (Alexia Michaelides - personal communication, 2019).

Going forward, we would like to refine and continue this study by expanding data collection across SA to inform national government, hospital administrators, transplant co-ordinators and referring medical professionals where the system can be improved to compassionately explore the option of organ and tissue donation in all appropriate cases, thereby improving access to life-saving transplants.

\section{Study limitations}

This was a descriptive study, which yielded a low sample size that is inadequately powered for meaningful comparative data analysis. Our methodology was based on the transplant co-ordinators' impression and not self-reported information by individuals and families approached for consent. No change was made to the transplant co-ordinators' standard practice; therefore, data recorded were those that occurred naturally in the course of the family approach, which resulted in incomplete data. Data were not collected immediately during the family approach and the retrospective recording of data

Table 6. NICE recommendations: Timely identification and referral of potential organ donors ${ }^{[14]}$

Recommends that hospital staff initiate discussions with a specialist nurse for organ donation when one of the following criteria are met

Defined clinical trigger factors in patients who have had a catastrophic brain injury, i.e.

- absence of $\geq 1$ cranial nerve reflexes; and

- Glasgow coma scale score of $\leq 4$ that is not explained by sedation; and/or a decision has been made to perform brainstem death tests, whichever occurs first

Intention to withdraw life-sustaining treatment in patients with a life-threatening or life-limiting condition, which will, or is expected to, result in circulatory death

NICE = National Institute for Health and Care Excellence. 
may have influenced the data quality. We only recorded family approaches and did not include referrals where the body was unidentified or referrals in the private sector for donation after circulatory death, as the private sector does not support this form of donation

\section{Conclusions}

In the Western Cape, consent rates were low for organ donation in the public and private sectors. The majority of donors came from the public sector, despite a lower consent rate. In this sector, the majority of donor families were approached in the emergency unit. We showed a low donor-referral rate in the private sector. Ongoing audits are required for continuous quality improvement, which is critical to afford all patients and families the opportunity to donate at the end of life. Interventions to improve donor identification, referral and to optimise the consent rate are needed, with many potential areas for improvement highlighted in this study.

\section{Declaration. None.}

Acknowledgements. Groote Schuur Hospital, Red Cross War Memorial Children's Hospital and the Netcare Hospital Group.

Author contributions. HB, DT: conception, design, data analysis and preparation of the manuscript; FM, AM: design, data collection, data analysis and preparation of the manuscript; LP, LH, BG, LS: data collection and data analysis.

Funding. None.

Conflicts of interest. None.

1. World Health Organization-Organizacion Nacional de Trasplantes. Data of the WHO-ONT Global Observatory on Donation and Transplantation. http://www.transplant-observatory.org/ (accessed 25 July 2019)

2. Rodriguez-Arias D, Wright L, Paredes D. Success factors and ethical challenges of the Spanish mode of organ donation. Lancet 2010;376(9746):1109-1112. https://doi.org/10.1016/s0140-6736(10)61342-6 3. Muller E, Thomson D, McCurdie F. Transplantation in South Africa. Transplantation 2015;99(4):643-645 https://doi.org/10.1097/tp.0000000000000712

4. Organ Donor Foundation. Organ Donor Foundation - aims and objectives. 2019. https://www.odf.org za/about-us/aims-and-objectives.html (accessed 25 July 2019).

5. Sobnach S, Borkum M, Hoffman R, et al. Medical students' knowledge about organ transplantation: A South African perspective. Transplant Proc 2010;42(9):3368-3371. https://doi.org/10.1016/j. transproceed.2010.08.036

6. Etheredge $\mathrm{H}$, Turner R, Kahn D. Public attitudes to organ donation among a sample of urban-dwelling South African adults: A 2012 study. Clin Transplant 2013:27(5):684-692. https://doi.org/10.1111/ctr.12200 7. Bhengu B, Uys H. Organ donation and transplantation within the Zulu culture. Curationis 2004;27(3):24-33. 7. Bhengu B, Uys H. Organ donation and transp
https://doi.org/10.4102/curationis.v27i3.995
8. Webb G, Phillips N, Reddiford S, et al. Factors affecting the decision to grant consent for organ donation: A survey of adults in England. Transplantation 2015;99(7):1396-1402. https://doi.org/10.1097/ tp.0000000000000504

9. National Institute for Health and Care Excellence Guidelines. Organ donation for transplantation: National Institute for Health and Care Excellence Guidelines. Organ donation for transplantation:
Improving donor identification and consent rates for deceased organ donation. 2016. https://www.nice, Improving donor identification and consent rates for deceased organ donation. 2016. https://wWw.nin.
org.uk/guidance/cg135/evidence/organ-donation-full-guideline-184994893 (accessed 16 June 2019).

10. Barber K, Falvey S, Hamilton C, et al. Potential for organ donation in the United Kingdom: Audit of intensive care records. BMJ 2006;332(7550):1124-1127. https://doi.org/10.1136/bmj.38804.658183.55

11. Etheredge HR, Penn C, Watermeyer J. A qualitative analysis of South African health professionals' discussion on distrust and unwillingness to refer organ donors. Progress Transplant 2018;28(2):163-169. https://doi.org/10.1177/1526924818765819

2. Slabbert M, Venter B. Routine referrals: A possible solution for transplantation shortages. S Afr J Bioethics Law 2017;10(1):15-19. https://doi.org/10.7196/sajbl.498

13. Bleakley G. Implementing minimum notification criteria for organ donation in an acute hospital's critical care units. Nursing Crit Care 2010;15(4):185-191. https://doi.org/10.1111/j.1478-5153.2009.00385.x

14. National Institute for Health and Care Excellence Guidelines. Timely identification and referral of potential organ donors. 2012. https://nhsbtdbe.blob.core.windows.net/umbraco-assets-corp/1337/timelyidentification-and-referral-of-potential-organ-donors-nhsbt.pdf (accessed 16 June 2019).

15. Centers for Medicare and Medicaid Services (CMS). Medicare and Medicaid programs; conditions for coverage for organ procurement organizations (OPOs). Final rule. Fed Regist 2006;71(104):3098131054

16. Fabre J, Murphy P, Matesanz R. Presumed consent: A distraction in the quest for increasing rates of organ donation. BMJ 2010;341:c4973. https://doi.org/10.1136/bmj.c4973

17. Fabre J. Presumed consent for organ donation: A clinically unnecessary and corrupting influence in medicine and politics. Clin Med 2014;14(6):567-571. https://doi.org/10.7861/clinmedicine.14-6-567

8. Sheehy E, Conrad SL, Brigham LE, et al. Estimating the number of potential organ donors in the United States. N Engl J Med 2003;349(7):667-674. https://doi.org/10.1056/nejm200311203492117

19. UK Health Department. Organs for transplants: A report from the Organ Donation Taskforce. 2008. https://nhsbtdbe.blob.core.windows.net/umbraco-assets-corp/4245/organsfortransplantstheorgandonortaskforcel streport.pdf (accessed 16 June 2019).

20. Rosendale JD, Chabalewski FL, McBride MA, et al. Increased transplanted organs from the use of a standardized donor management protocol. Am J Transplant 2002;2(8):761-768. https://doi.org/10.1034/ j.1600-6143.2002.20810.x

21. Malinoski DI, Daly MC, Patel MS, et al. Achieving donor management goals before deceased donor Malinoski DJ, Daly MC, Patel MS, et al. Achieving donor management goals before deceased donor
procurement is associated with more organs transplanted per donor. J Trauma Acute Care Surg 2011:71(4):990-996. https://doi.org/10.1097/ta.0b013e31822779e5

22. Simpkin AL, Robertson LC, Barber VS, et al. Modifiable factors influencing relatives' decision to offer organ donation: Systematic review. BMJ 2009;338:b991. https://doi.org/10.1136/bmj.b991

23. Lavee J, Ashkenazi T, Stoler A, et al. Preliminary marked increase in the national organ donation rate in Israel following implementation of a new organ transplantation law. Am J Transplant 2013;13(3):780-785. https://doi.org/10.1111/ajt.12001

24. Lavee J, Ashkenazi T, Gurman G, et al. A new law for allocation of donor organs in Israel. Lancet 2010;375(9720):1131-1133. https://doi.org/10.1016/s0140-6736(10)61137-3

25. Reyneke M. Understanding decisional conflict amongst family members in organ donation in the Western Cape Province. MCur. Potchefstroom: North-West University, 2014.

26. United Kingdom Cabinet Office Behavioural Insights Team. Applying Behavioural Insights to Organ Donation: Preliminary Results From a Randomised Controlled Trial. London: Cabinet Office, 2013. https://assets publishing service ov uk/government/uploads/system/uploads/attachment_data/ file/267100/Applying_Behavioural_Insights_to_Organ_Donation.pdf (accessed 16 June 2019).

27. Etheredge H. Opt-in or opt-out to increase organ donation in South Africa? Appraising proposed Etheredge $\mathrm{H}$. Opt-in or opt-out to increase organ donation in South Africa? Appraising proposed
strategies using an empirical ethics analysis. Develop World Bioethics 2017;18(2):119-125. https://doi. org/10.1111/dewb.12154

28. Du Toit T, Manning K, Thomson D, et al. Kidney transplantation utilising donors after circulatory death - the first report from the African continent. Transplantation 2018;102:S493-S494. https://doi. org/10.1097/01.tp.0000543311.81537.58

29. Taskforce Organ Donation. Annual Activity Report - United Kingdom. 2017 - 2018. https://nhsbtdbe. blob.core.windows.net/umbraco-assets-corp/12300/transplant-activity-report-2017-2018.pdf (accessed 16 June 2019)

Accepted 23 August 2019. 